\title{
Long Term Corrosion Protection of Epoxy Coating Containing Tetraaniline Nanofiber
}

\author{
Feng Yang ${ }^{1}$, Tong Liu ${ }^{1,2}$, Jingyu Li ${ }^{1,2}$, Haichao Zhao ${ }^{2, *}$ \\ ${ }^{1}$ Shenyang University of Chemistry and Technology, Shenyang, 110142, P. R. China \\ ${ }^{2}$ Key Laboratory of Marine Materials and Related Technologies, Zhejiang Key Laboratory of Marine \\ Materials and Protective Technologies, Ningbo Institute of Materials Technology and Engineering, \\ Chinese Academy of Sciences, Ningbo 315201, P. R. China. \\ *E-mail: zhaohaichao@nimte.ac.cn
}

doi: $10.20964 / 2018.07 .52$

Received: 24 November 2017 / Accepted: 11 January 2018 / Published: 5 June 2018

\begin{abstract}
A supermolecular assembly chemistry was applied to aniline based oligomer, tetraaniline (TANI), in 1 $\mathrm{M} \mathrm{HCl}$ aqueous solution to obtain nanofibrous emeraldine salt of TANI (TANI-ES), making it suitable as novel anticorrosive inhibitor for primer coatings. Epoxy coating pigmented with $0.5 \mathrm{wt} \%$ and $1 \mathrm{wt} \%$ TANI-ES were then prepared by curing reaction of epoxy E44, polyamide hardener with the existence of TANI-ES. The corrosion behavior of the coatings without and with $0.5 \mathrm{wt} \%$ and $1.0 \mathrm{wt} \%$ TANI-ES on Q235 steel in the $3.5 \mathrm{wt} \% \mathrm{NaCl}$ solution was investigated by open circuit potential (OCP) test, electrochemical impedance spectroscopy (EIS) measurements, scanning vibrating electrode technique (SVET) as well as salt spray test. Results suggested that synthesized epoxy composite coatings, particularly with $0.5 \mathrm{wt} \%$ TANI-ES nanofiber coating, exhibited exceptional anticorrosion capability compared with the pure epoxy E44 coating. The salt spray test exhibited that $0.5 \mathrm{wt} \%$ conducting polymer coating possessed excellent salt-fog-resistance property with slight rust formation and blistering resistance on the steel sheets.
\end{abstract}

Keywords: tetraaniline; nanofiber; epoxy coating; anticorrosion

\section{FULL TEXT}

(C) 2018 The Authors. Published by ESG (www.electrochemsci.org). This article is an open access article distributed under the terms and conditions of the Creative Commons Attribution license (http://creativecommons.org/licenses/by/4.0/). 